\title{
CORRECTION
}

\section{Correction to: Task-switching abilities in episodic and chronic migraine}

\author{
Simone Migliore ${ }^{1}$ - Giulia D'Aurizio ${ }^{2}$. Claudia Altamura ${ }^{3} \cdot$ Nicoletta Brunelli $^{3}$. Carmelinda Costa ${ }^{3} \cdot$ Giuseppe Curcio $^{2}$. \\ Fabrizio Vernieri $^{3}$
}

Published online: 7 February 2022

(c) Fondazione Società Italiana di Neurologia 2022

\section{Correction to: Neurological Sciences (2022) \\ https://doi.org/10.1007/s10072-021-05837-4}

The original published online version contains inverted names of the Authors. The correct presentations are given above.

The original article has been corrected.

Publisher's Note Springer Nature remains neutral with regard to jurisdictional claims in published maps and institutional affiliations.

The original article can be found online at https://doi.org/10.1007/ s10072-021-05837-4.

Simone Migliore

sim.migliore@gmail.com

1 Huntington and Rare Diseases Unit, Fondazione IRCCS

Casa Sollievo Della Sofferenza, San Giovanni Rotondo, Italy

2 Department of Biotechnological and Applied Clinical Sciences, University of L'Aquila, L'Aquila, Italy

3 Headache and Neurosonology Unit, Policlinico Universitario Campus Bio-Medico, Rome, Italy 